\title{
Article
}

\section{Mapping Spatial Distribution of Pores in an Additively Manufactured Gold Alloy Using Neutron Microtomography}

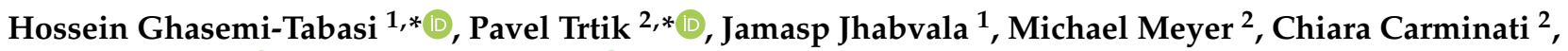 \\ Markus Strobl ${ }^{2}$ (D) and Roland E. Logé ${ }^{1}$ (D) \\ 1 Thermomechanical Metallurgy Laboratory (LMTM)—PX Group Chair, École Polytechnique Fédérale de \\ Lausanne (EPFL), 2002 Neuchâtel, Switzerland; jamasp.jhabvala@epfl.ch (J.J.); roland.loge@epfl.ch (R.E.L.) \\ 2 Laboratory for Neutron Scattering and Imaging (LNS), Paul Scherrer Institut, 5232 Villigen PSI, Switzerland; \\ migi.meyer@psi.ch (M.M.); chiara.carminati@psi.ch (C.C.); markus.strobl@psi.ch (M.S.) \\ * Correspondence: hossein.ghasemitabasi@epfl.ch (H.G.-T.); pavel.trtik@psi.ch (P.T.)
}

check for updates

Citation: Ghasemi-Tabasi, H.; Trtik, P.; Jhabvala, J.; Meyer, M.; Carminati, C.; Strobl, M.; Logé, R.E. Mapping Spatial Distribution of Pores in an Additively Manufactured Gold Alloy Using Neutron Microtomography. Appl. Sci. 2021, 11, 1512. https:// doi.org/10.3390/app11041512

Academic Editor: Wolfgang Treimer Received: 12 January 2021

Accepted: 3 February 2021

Published: 8 February 2021

Publisher's Note: MDPI stays neutral with regard to jurisdictional claims in published maps and institutional affiliations.

Copyright: (c) 2021 by the authors. Licensee MDPI, Basel, Switzerland. This article is an open access article distributed under the terms and conditions of the Creative Commons Attribution (CC BY) license (https:/ / creativecommons.org/licenses/by/ $4.0 /)$.

\begin{abstract}
A crucial criterion for the quality of the additively manufactured parts is the porosity content for achieving an acceptable final relative density. In addition, for jewelry applications, visible pores are unacceptable at or in the vicinity of the surface. In this study, non-destructive 3D neutron microtomography is applied to map the spatial distribution of pores in additively manufactured red-gold samples. The 3D imaging assessment underlines the high relative density of the printed red-gold sample and indicates residual pore sizes are predominantly below the limit of concern for jewelry applications. The 3D maps of pores within printed samples highlight the effect of the scanning strategy on the final quality and location of pores in the printed samples. These results confirm that neutron microtomography is a novel and precise tool to characterize residual porosity in additively manufactured gold alloys and other higher-Z materials where such investigation using other non-destructive methods (such as X-rays) is challenging due to the limited penetration depth.
\end{abstract}

Keywords: laser powder bed fusion; non-destructive investigations; gold alloy; neutron microtomography; porosity

\section{Introduction}

Additive manufacturing ( $\mathrm{AM}$ ) refers to different technologies that produce a 3D part in a layer-by-layer mode. Laser powder bed fusion (L-PBF), also known as selective laser melting (SLM), is one of the most important powder bed fusion AM processes, which enables the manufacturing of very complex metallic objects from a computer-aided design (CAD) file. Printing parts with L-PBF technology requires careful optimization of the process parameters, which depend on the metallic powder and its physical and chemical properties [1,2]. Materials with high reflectivity and high thermal conductivity, such as gold and its alloys, are usually difficult to process because they are hard to heat and maintain in a stable molten state. Moreover, for printing in commercial machines, a non-negligible amount of metallic powder is needed to fill the powder supply, which tends to make AM of gold alloys rather uneconomical. Despite these obstacles, L-PBF of precious metals, including gold, is receiving increasing interest, in particular, from the jewelry and watch industries [3-7].

One of the main criteria for the success of AM-produced parts is the porosity content. The occurrence of pores in gold alloys produced by AM is very difficult to avoid. At the same time, it is critical for applications in jewelry and watches to minimize porosity and, in particular, when it could be visible on the material surface. The latter implies that the pore size, especially in the surface region, is required to be smaller than approximately 15-20 microns. Otherwise, the pores can be observed with the naked eye, and even if they are located in close vicinity of the surface, they can appear later due to material wear. 
Conventionally, porosity in a bulk material can be investigated using the Archimedes method, microscopy, or X-ray tomography. However, all of these methods are of limited use for AM-produced gold alloys. The Archimedes method [8] has been used in different studies to evaluate the relative density of parts $[9,10]$. In L-PBF processing, due to the geometrical constraints and/or partial consolidation of powder particles, there might be particles left inside of pores after build completion [11]. Since the used immersion liquid cannot wet rough surfaces efficiently and also does not take these internally trapped powders into consideration, the Archimedes method is not a very reliable technique to precisely measure the porosity content in L-PBF samples. Furthermore, as the size of the precious metal samples is usually limited, the confidence level of the Archimedes method is low. Above all, the Archimedes method does not provide any information about the pore size and spatial distributions within the material, which are important parameters with respect to the abovementioned requirements [12].

Likewise, the high cost associated with material loss also seriously limits the use of optical microscopy on mechanical sections of representative volumes. Klotz et al. [7] conducted a full process study on the L-PBF of yellow gold alloys and analyzed the porosities in the printed samples by mechanical polishing. The effects of the heat treatment and alloying addition ( $\mathrm{Fe}$ and $\mathrm{Ge}$ ) on the optical reflectivity and, as a result, on the final porosity were analyzed. The average porosity using untreated powder particles was in the order of $3 \%$ to $4 \%$. With the use of thermal heat treatment and alloying, Klotz et al. could decrease the final porosity to $0.7 \%$ and $0.1-0.3 \%$, respectively. They used the addition of Ge to the yellow gold chemical composition to lower the solidus temperature, which provided easier conditions to melt the material. Moreover, the addition of Fe increased the oxidation of the powder particles and, as a result, decreased their reflectivity.

In general, quantitative investigations can be performed using X-ray tomography [13-18]. For example, Cai et al. [19] observed the internal structure of AlSi10Mg L-PBF-printed samples to investigate the effect of the process parameters on the final porosity content, and to provide knowledge to control the quality of L-PBF parts. However, the penetration depth of X-rays in gold alloys is rather limited [20], which makes the investigation of representative volume elements hardly possible.

Neutron tomography provides a viable alternative to visualize the distribution of pores in additively manufactured samples [21]. Here, recent advances in the available instrumentation have been utilized $[22,23]$ that allow resolution of features with dimensions of a few micrometers [24]. The neutron cross-section of gold and, hence, the penetration depth of thermal neutrons for gold alloys is such that it provides excellent transmission imaging contrast conditions for samples in the range of several millimeters in thickness. Thus, imaging with neutrons has evolved to be a highly suitable experimental technique for studying the relationship between porosity and L-PBF processing parameters in samples opaque to X-rays. While a proof-of-concept neutron microtomography experiment with high-resolution detector capability at Paul Scherrer Institut (PSI) [25] recently demonstrated the feasibility to assess porosity in gold at about $10 \mu \mathrm{m}$ spatial resolution, we focus, here, on the assessment of porosity in gold alloy samples of representative volumes manufactured by L-PBF.

\section{Materials and Methods}

Two samples of 18-carat red-gold alloy ( $\mathrm{Au}_{511} \mathrm{Cu}_{433} \mathrm{Ag}_{56}$, expected density $15.2 \mathrm{~g} \mathrm{~cm}^{-3}$ ) of the intended size of $2 \times 2 \times 2 \mathrm{~mm}^{3}$ have been printed with an in-house customized L-PBF machine, dedicated to research activities and designed for operating with a low amount of powder [26] using the process parameters shown in Table 1. In the L-PBF processes, the scanning of the laser beam for each layer follows specific patterns called scanning strategies, and the hatching distance defines the separation between two consecutive laser tracks [27]. In this study, two different scanning strategies are used, parallel and crosshatch. The parallel scan path is the most frequently applied scanning strategy for L-PBF in which parallel unidirectional tracks are traced with a fixed distance (hatching distance) between 
adjacent tracks. At the end of each track, there is a discontinuous jump of the laser beam from the end of one track to the beginning of the next track. The crosshatch scanning strategy consists of two parallel scan paths which are perpendicular to each other, and both are applied on each layer [28].

Table 1. Laser powder bed fusion (L-PBF) process parameters for two red-gold samples.

\begin{tabular}{cccccc}
\hline Sample & Power $(\mathbf{W})$ & Speed $(\mathbf{m m} / \mathbf{s})$ & $\begin{array}{c}\text { Hatching } \\
\text { Distance }(\mu \mathrm{m})\end{array}$ & $\begin{array}{c}\text { Layer Thickness } \\
(\mu \mathrm{m})\end{array}$ & $\begin{array}{c}\text { Scanning } \\
\text { Strategy }\end{array}$ \\
\hline 1 & 210 & 220 & 100 & 40 & Parallel \\
\hline 2 & 230 & 200 & 70 & 40 & Crosshatch \\
\hline
\end{tabular}

The L-PBF machine is equipped with a $500 \mathrm{~W}$ fiberlaser (SPI, Southampton, UK.) with a wavelength of $1070 \mathrm{~nm}$ and a laser spot diameter of $85 \mu \mathrm{m}$. Information on the applied optimization process determined via experiments and simulation can be found in [26]. First, analyses confirmed major improvements in printing gold samples with high relative density, compared, e.g., to previous studies where the chemical composition of the alloy had to be altered to print samples with a reasonably low amount of porosity [7].

The process parameters were selected such as to reach the highest possible relative density in one sample (Sample 1) and allowing for a higher porosity content and higher amount of partially melted zones in the other (Sample 2). This is done in order to not only investigate a sample of low porosity from a process that is assumed to be optimized but also to establish confidence in the method by detecting higher porosity from a less optimized process.

The presented investigation has been performed with the high-resolution imaging detector [29] of PSI at the D50 beamline of the ILL (Institute Laue Langevin) [30]. Neutron microscope installed at ILL-D50 beamline allowed for 2D images of the Siemens star to be positioned in contact with the scintillator screen and showed the spatial resolution of approximately $5 \mu \mathrm{m}$ [29]. The scintillator screen $\left({ }^{157} \mathrm{Gd}_{2} \mathrm{O}_{2} \mathrm{~S}: \mathrm{Tb}\right.$ [31]) of the detector system has been positioned at $11.13 \mathrm{~m}$ downstream of the $30 \mathrm{~mm}$ diameter pinhole, thus providing a neutron beam collimation ratio of 371 . The light emitted from the scintillator has been captured by a CCD camera (Andor iKon-L, $2048 \times 2048$ pixels, $13.5 \mu \mathrm{m}$ pixel size). Due to the fivefold magnification of the high-resolution detector, the effective pixel size of the acquired images was $2.7 \mu \mathrm{m}$, and the available image field of view (FOV) was $5.5 \times 5.5 \mathrm{~mm}^{2}$.

The samples were attached to sample holders using UV-hardening glue, and both were scanned in a single tomographic run using 375 projections evenly distributed between 0 and $359.04^{\circ}$. Five images with $30 \mathrm{~s}$ exposure time were acquired for each angular position that were after the white spot (gamma ray artifacts) removal averaged in a single projection image. The tomographic measurement was complemented with the acquisition of 100 open beam images without sample, 30 dark current images, as well as the acquisition of black body (BB) images for background correction according to references [32,33]. The individual projections were aligned during post-processing to correct for the sample positioning instabilities using an alignment algorithm originally developed for X-ray ptychographic tomography [34]. The tomographic dataset was reconstructed using the MuhRec software [35]. Ring artifacts were suppressed by a combined wavelet-Fourier stripe cleaning algorithm [36]. The tomographic dataset was then post-processed using the Kiptool software [37] with an edge-preserving smoothing inverse scale space (ISS) filter [38]. The dataset visualizations and quantitative analysis were subsequently performed using Avizo 3D visualization software.

The linear attenuation coefficient (LAC) of the gold alloy has been found to be about $6.55 \mathrm{~cm}^{-1}$. This value is in rather good agreement with the theoretically predicted value $\left(6.43 \mathrm{~cm}^{-1}\right)$ [39] for the mentioned red-gold alloy composition at $2.8 \AA$ neutron wavelength (peak wavelength of the neutron spectrum at D50 beamline). The porosity has been 
segmented using the Otsu method [40], setting the global threshold between gold alloy and hollow space to $3.226 \mathrm{~cm}^{-1}$. Subsequently, the closed porosity volume fractions in both samples have been analyzed.

\section{Results and Discussion}

Figure 1 concisely summarizes the results of the porosity quantification based on neutron microtomography and shows the $3 \mathrm{D}$ renderings of both samples, revealing the sample shape and the spatial distribution of the closed pores (in blue) larger than 10 micrometers in equivalent diameter. The pore size distributions of the closed pores differ significantly between the two samples, and for the large pores (larger than 10 micrometers), the fractions are $0.012 \%$ and $0.047 \%$, respectively.
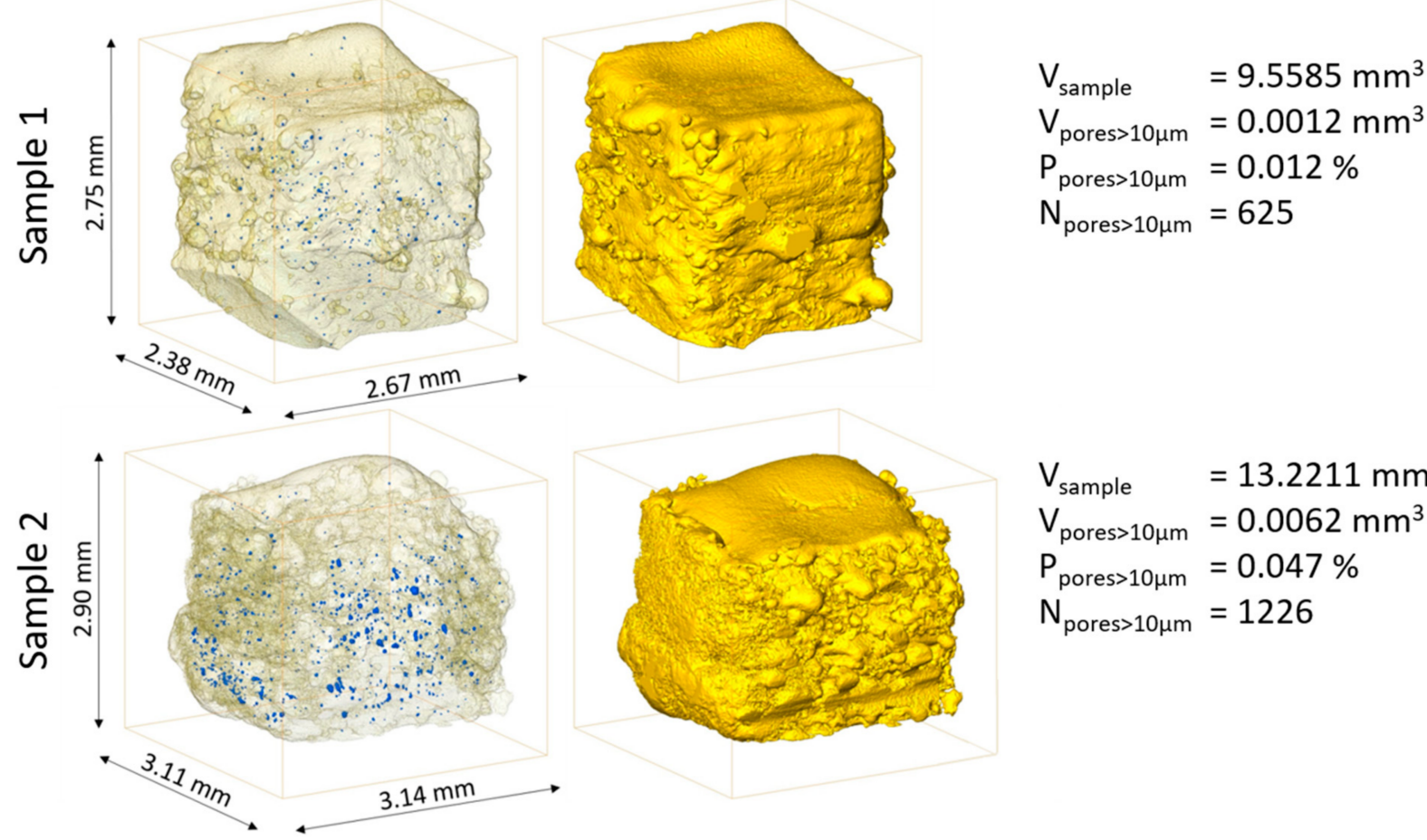

Figure 1. 3D renderings of the L-PBF-printed red-gold samples revealing sample shapes and their closed porosities in blue. For each sample, the number of pores $>10 \mu \mathrm{m}$ (all pores which are larger than $10 \mu \mathrm{m}$ ) and their volume relative to the total sample volume has been quantified.

Higher laser power and lower hatching distance used in the manufacturing process of Sample 2 increased the heat accumulation [41] and, as a result, the amount of sintered powder at the border of the samples. Moreover, in the crosshatch scanning strategy, which is used for Sample 2, the laser passes two times in each layer, in two directions perpendicular to each other, which also increases the total heat input and leads to the formation of large fractions of sintered powders at the sample edges. By contrast, in Sample 1, using optimal process parameters and a parallel scanning strategy, the fraction of sintered powder at the sample surface is reduced. These surface features explain the relatively large difference between the total volumes of Samples 1 and 2.

The investigated samples have been printed with an in-house customized L-PBF machine that is not equipped with contour correction algorithms. Such options exist in some machines, and they may improve the sample quality (e.g., its final shape) at the borders and edges [42].

Figure 2 shows optical microscopy images acquired after neutron microtomography, following the mechanical sectioning of the samples (Figure 2b,e). Juxtaposed are the corresponding sections from the 3D neutron microtomography reconstructions (Figure 2a,d). 
The location of the corresponding section in the neutron tomographic datasets is difficult to precisely identify for several reasons: (a) the real metallographic sections may not necessarily be planar, (b) the preparation of the metallographic section may lead to relocation of some parts of the sample, in particular, within the sintered zones at the edges of the sample. Despite this fact, the image comparison indicates a very good match between 2D optical microscopy and 3D neutron microtomography cross-sections.
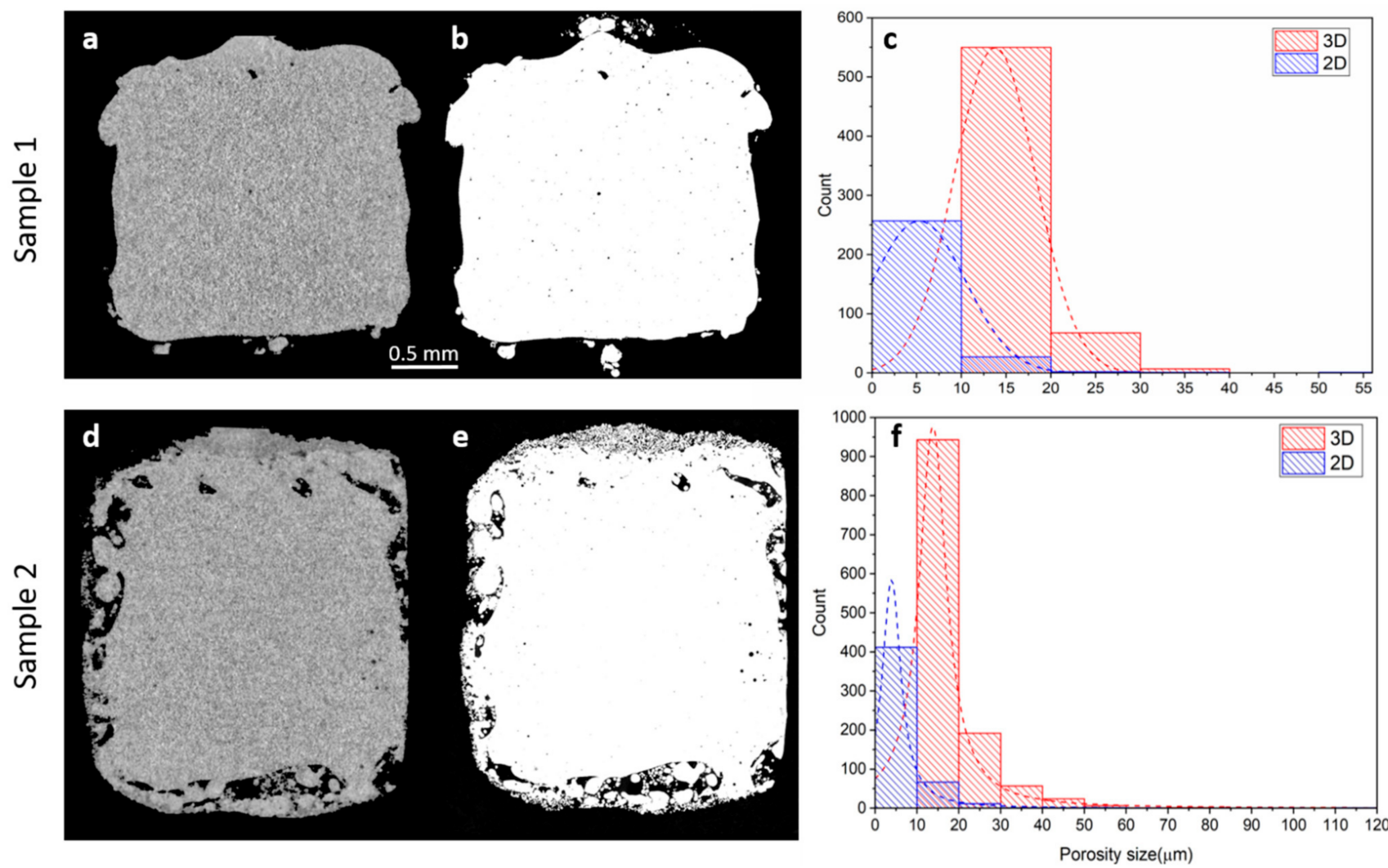

Figure 2. Comparison of the neutron microtomography $(\mathbf{a}, \mathbf{d})$ sections and their equivalent optical microscopy (b,e) sections. Graphs $(\mathbf{c}, \mathbf{f})$ show pore size distributions extracted from the full volume of the 3D neutron microtomography datasets and from a single slice of optical microscopy $(\mathbf{b}, \mathbf{e})$ sections, respectively.

Figure $2 \mathrm{c}, \mathrm{f}$ show the pore size distribution based on the neutron microtomography (3D) and optical microscopy (2D). The neutron tomography data reveals the following. The number of individual pore entities in Sample 2 is almost two-times larger compared to Sample 1, with a considerable number of large pores (larger than 30 micrometers). The pore size distribution indicates that almost $88 \%$ of the total porosity in Sample 1 is composed of pores smaller than $15 \mu \mathrm{m}$ (critical pore size for watch and jewelry industry), which are generally due to entrapped gas in powder particles [43]. There are only six pores in the entire sample volume with an equivalent diameter larger than $30 \mu \mathrm{m}$. On the other hand, Sample 2 exhibits a larger number of pores, in particular, also with increased sizes (90 pores larger than $30 \mu \mathrm{m}$ ), and only $55 \%$ of the total porosity corresponds to pores smaller than $15 \mu \mathrm{m}$. These results show a significant improvement in the choice of the optimum process parameters for printing red-gold samples and highlight the effect of the scanning strategy on the final quality of the printed samples. Although the initial porosity entrapped in powder particles cannot fully account for the total amount of porosities in the printed samples, increasing powder quality would further improve density, e.g., by using the plasma rotating electrode process (PREP) [43,44].

Pore size analysis from the optical microscopy cross-sections indicates that most of the pores are actually much smaller than 10 micrometers (Figure 2c,f) and, thus, below the current resolution of the neutron microtomography datasets. However, the comparison of 
relative densities from the optical 2D section and the corresponding 2D slice of the 3D data (see Figure $2 \mathrm{a}-\mathrm{d}$ ) reveals that the contribution of pores smaller than 10 micrometers to the total relative density of the printed samples is negligible. Density values acquired from 2D optical microscopy (99.73\% and $98.35 \%$ for Samples 1 and 2, respectively), and from the corresponding 2D slices of 3D neutron microtomography data $(99.81 \%$ and $98.42 \%$ for Samples 1 and 2, respectively) are indeed very close. The difference in relative density with and without considering pores smaller than 10 micrometers in the equivalent diameter is less than $0.1 \%$. It should be noted that in $2 \mathrm{D}$ optical microscopy cross-sections, there is a contribution of open porosity to what appears to be closed porosity; however, the provision of the 3D datasets reveals such artefacts.

Figure 3 shows the 3D distribution of pores in Samples 1 and 2, with equivalent diameter color coding. Figure $3 \mathrm{c}$, d give distributions from the top view, along the building direction, revealing pore locations with respect to the intended production volume. A strong correlation with the scanning strategy is observed. Although pores in Sample 1 are much more homogeneously distributed than in Sample 2, in both samples, most of the pores are located at specific surface regions corresponding to laser off events. Laser off events refer to the end of the scanning along each scan line, where the scanning speed changes to lower values before the laser is completely turned off, resulting in a local increase of heat input, causing material evaporation and porosity formation [45]. A larger fraction of pores appear, in particular, outside the intended sample production volume. This is much more pronounced in the case of Sample 2, manufactured with lower hatching distance and higher laser power (see Table 1). In Sample 1, this type of porosity is significantly lower and limited to $9 \%$ (10\% volume-wise) of the total number of closed pores larger than 10 micrometers. By contrast, these amount to $52 \%$ (54\% volume-wise) in Sample 2.

However, in the jewelry and watch industries, part contours are post-processed with surface treatments to ensure mirror-polished surfaces. Our interest, therefore, mainly lies in the porosity within the target shape of the samples. Figure 3e,f represent the distribution of visualized pores at the surface of the target shape of the printed samples. The results indicate very few pores are found at the target surface of Sample 1. On Sample 2, significant porosity is revealed at the target surface. Considering the surface with the highest porosity in both samples, relative density at the surface for Sample 1 is $99.98 \%$, whereas for sample 2 , it is only about $99.60 \%$.

3D analysis of pore morphologies in additively manufactured samples helps to distinguish different types of pores. Most of the pores in Samples 1 and 2 are close to spherical. These round pores (e.g., Figure 4a) form due to the injection of dissolved gas at the liquidsolid interface. Spherical pores typically have four different origins: (i) the moisture absorbed by the powder particles in the ambient atmosphere, (ii) shielding gas during the manufacturing process, (iii) gas entrapped inside the powder particles during the powder atomization process, and (iv) entrapment of the gas during the manufacturing process due to alloy vapors inside the molten pool [46,47].

Figure $4 \mathrm{~b}$ shows an example of a large pore in Sample 2, which can be assumed to have formed due to keyhole collapse and shrinkage during L-PBF processing. The higher energy density used for printing Sample 2 increases the chance for keyhole formation [48]. Figure $4 \mathrm{~b}$ indicates a prolate spheroid shape pore located close to the sample edge. As discussed earlier, higher energy densities at the end of a laser track lead to keyhole pore formation. Considering the physical limitations of the laser scanning system optics, stabilizing the energy density by varying the laser power is a solution to solve this problem [43,49]. This emphasizes the fact that modification of process parameters is a practical approach to control defect formation (pores, cracks, etc.) in the final printed samples [50,51]. 

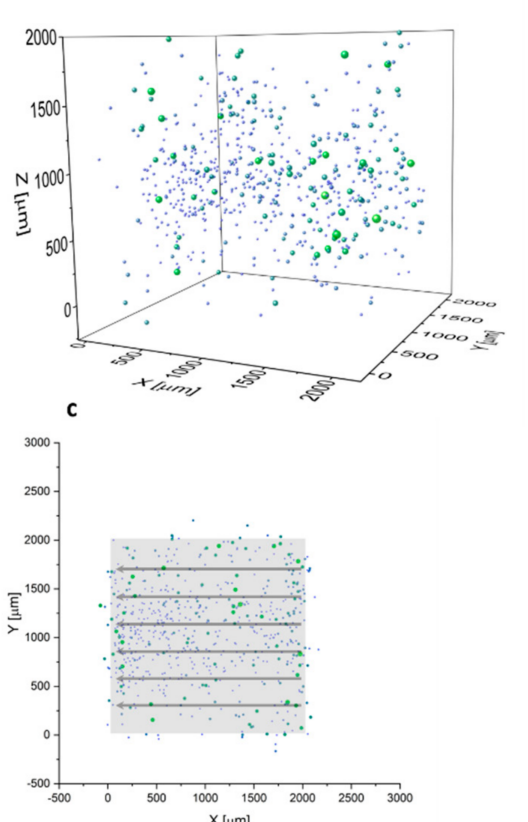

Equivalent pore diameter [um]

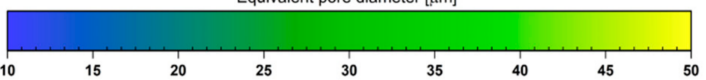

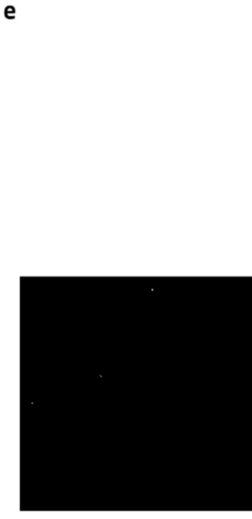

$\mathrm{X}=0 \mathrm{~mm}$

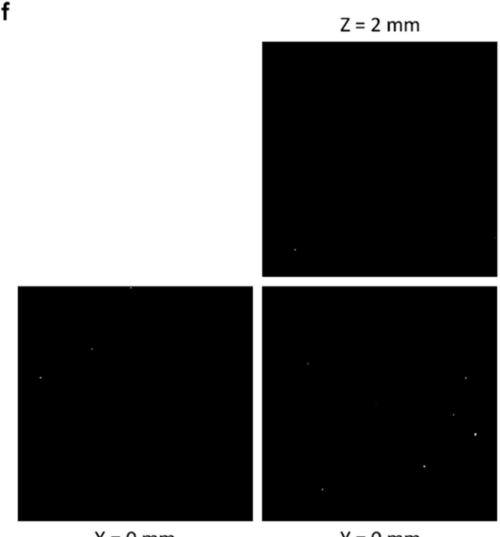

$\mathrm{X}=0 \mathrm{~mm}$

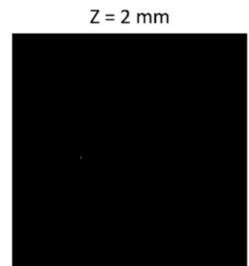

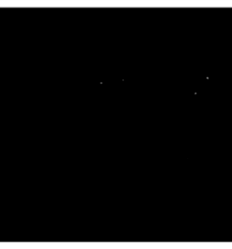

$\mathrm{Y}=0 \mathrm{~mm}$

$\mathrm{Y}=0 \mathrm{~mm}$
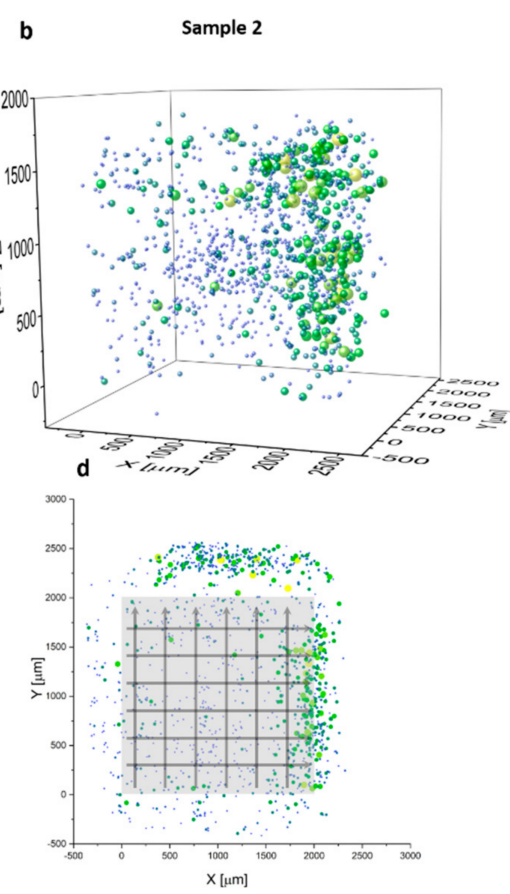

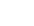




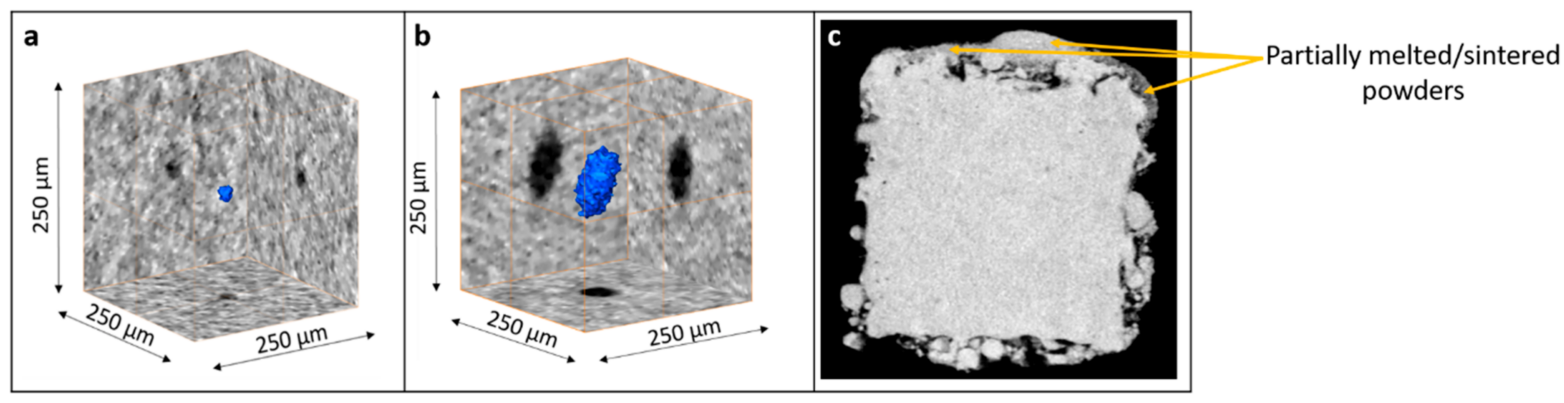

Figure 4. Different types of pores in L-PBF-printed red-gold samples characterized by neutron microtomography: (a) round pore, (b) large keyhole pore, and (c) partially melted/sintered powders at the edge of the printed sample.

Irregular pores located in the vicinity of the part surface are due to partially melted/ sintered/entrapped metallic powder particles, which stick to and agglomerate on the outer edge of the melt pool. These residual powders are associated with the presence of complex voids, which can be distinguished from other types of defects [52,53]. The specific process parameters of Sample 2 (i.e., higher power, lower speed, smaller hatching distance) lead to higher energy density, which leads to the accumulation of more heat during the printing process. This heat input diffuses up to hundreds of micrometers from the melt pool and increases the temperature of the surrounding powder. Some of the powder grains will thus sinter or partially melt, leading to their agglomeration to the solidified surfaces [54], as visualized in Figure 4c. Due to their sub-10-micrometers size, the induced porosities cannot be analyzed in detail using 3D neutron microtomography. However, the partially melted zones exhibit significantly lower LAC than the well-processed zones and can, therefore, be clearly distinguished (Figure 4c).

\section{Conclusions}

In summary, it has been demonstrated here that the direct additive manufacturing of gold alloys of very low total porosity is possible without the need of any additional postprocessing or alloying. This makes the analyzed production parameters directly applicable for the production processes in the jewelry and watch industries. In addition, the results highlight the effect of the scanning strategy on the final quality and pore distribution of the printed samples. Likewise, the results show that neutron microtomography is an excellent tool to characterize relevant residual porosity in additively manufactured gold alloys and other higher-Z materials.

Author Contributions: Conceptualization, H.G.-T., P.T., J.J., M.S. and R.E.L.; Data curation, P.T.; Formal analysis, H.G.-T., P.T., M.M., C.C. and M.S.; Funding acquisition, R.E.L., P.T.; Investigation, H.G.-T., P.T., J.J., M.M. and C.C.; Methodology, H.G.-T., P.T.; Project administration, P.T., J.J., M.S. and R.E.L.; Resources, P.T., R.E.L.; Software, P.T.; Supervision, J.J., P.T., M.S. and R.E.L.; Validation, H.G.-T., P.T., J.J., M.M., C.C. and M.S.; Visualization, P.T., H.G.-T.; Writing-original draft, H.G.-T., P.T.; Writing—review \& editing, H.G.-T., P.T., J.J., M.S. and R.E.L. All authors have read and agreed to the published version of the manuscript.

Funding: This work has been supported by the "Additive Manufacturing and Metallic Microstructures (AM3)" project. The project is funded by the Competence Center for Materials Science and Technology (CCMX) and by a Swiss industrial consortium.

Institutional Review Board Statement: Not applicable.

Informed Consent Statement: Not applicable.

Data Availability Statement: The data that support the findings of this study are available from the corresponding author upon reasonable request. 
Acknowledgments: The generous support of PX Group to the LMTM laboratory is highly acknowledged. We would like to express the deepest gratitude to Duncan Atkins and Alessandro Tengattini (both ILL, Grenoble, France) for the assistance with setting up the Neutron Microscope detector at ILL-D50 beamline.

Conflicts of Interest: The authors declare that they have no known competing financial interests or personal relationships that could have appeared to influence the work reported in this paper.

\section{References}

1. Masmoudi, A.; Bolot, R.; Coddet, C. Investigation of the laser-powder-atmosphere interaction zone during the selective laser melting process. J. Mater. Process. Technol. 2015, 225, 122-132. [CrossRef]

2. Pupo, Y.; Monroy, K.P.; Ciurana, J. Influence of process parameters on surface quality of CoCrMo produced by selective laser melting. Int. J. Adv. Manuf. Technol. 2015, 80, 985-995. [CrossRef]

3. Cooper, F. DMLM Supports: Are They the Jewelry Industry's New Sprue, Riser and Gate Feed. In The Santa Fe Symposium on Jewelry Technology; Santa Fe Symposium: Albuquerque, NM, USA, May 2014; pp. 1-22.

4. Fischer-Buehner, J.; Poliero, P.; Bertoncello, R.; Basso, A.; Fischer-buehner, J.; Poliero, M. Rapid Jewelry Manufacturing By Laser Melting of Precious Metal Powders (PLM): Fiction Or Future. In The Santa Fe Symposium on Jewelry Manufacturing Technology; Santa Fe Symposium: Albuquerque, NM, USA, May 2011; pp. 177-202.

5. Zito, D.; Carlotto, A.; Loggi, A.; Sbornicchia, P.; Maggian, D.; Progold, S.A.; Vi, T.; Fockele, M.; Unterberg, P. Optimization of the Main Selective Laser Melting Technology Parameters in the Production of Precious Metal Jewelry. In The Santa Fe Symposium on Jewelry Manufacturing Technology; Santa Fe Symposium: Albuquerque, NM, USA, May 2013; pp. 1-20.

6. Zito, D.; Carlotto, A.; Loggi, A.; Sbornicchia, P.; Bruttomesso, D.; Progold, S.A. Definition and solidity idity of gold and platinum jewels produced using Selective Laser Melting SLM ${ }^{\mathrm{TM}}$ technology. In The Santa Fe Symposium on Jewelry Manufacturing Technology; Santa Fe Symposium: Albuquerque, NM, USA, May 2015; pp. 439-470.

7. Klotz, U.E.; Tiberto, D.; Held, F. Optimization of 18-karat yellow gold alloys for the additive manufacturing of jewelry and watch parts. Gold Bull. 2017, 50, 111-121. [CrossRef]

8. Archimedes; Archimedes ON FLOATING BODIES, BOOK I. The Works of Archimedes; Dover Publications: Mineola, NY, USA, 2010; pp. 253-262.

9. Spierings, A.B.; Schneider, M.; Eggenberger, R. Comparison of density measurement techniques for additive manufactured metallic parts. Rapid Prototyp. J. 2011, 17, 380-386. [CrossRef]

10. Obaton, A.-F.; Lê, M.-Q.; Prezza, V.; Marlot, D.; Delvart, P.; Huskic, A.; Senck, S.; Mahé, E.; Cayron, C. Investigation of new volumetric non-destructive techniques to characterise additive manufacturing parts. Weld. World 2018, 62, 1049-1057. [CrossRef]

11. Hunter, L.W.; Brackett, D.; Brierley, N.; Yang, J.; Attallah, M.M. Assessment of trapped powder removal and inspection strategies for powder bed fusion techniques. Int. J. Adv. Manuf. Technol. 2020, 106, 4521-4532. [CrossRef]

12. Du Plessis, A.; Sperling, P.; Beerlink, A.; Tshabalala, L.; Hoosain, S.; Mathe, N.; le Roux, S.G. Standard method for microCT-based additive manufacturing quality control 2: Density measurement. MethodsX 2018, 5, 1117-1123. [CrossRef]

13. Limodin, N.; Salvo, L.; Suéry, M.; DiMichiel, M. In situ investigation by X-ray tomography of the overall and local microstructural changes occurring during partial remelting of an Al-15.8 wt.\% Cu alloy. Acta Mater. 2007, 55, 3177-3191. [CrossRef]

14. Maskery, I.; Aboulkhair, N.T.; Corfield, M.R.; Tuck, C.; Clare, A.T.; Leach, R.K.; Wildman, R.D.; Ashcroft, I.A.; Hague, R.J.M. Quantification and characterisation of porosity in selectively laser melted Al-Si10-Mg using X-ray computed tomography. Mater. Charact. 2016, 111, 193-204. [CrossRef]

15. Ziółkowski, G.; Chlebus, E.; Szymczyk, P.; Kurzac, J. Application of X-ray CT method for discontinuity and porosity detection in 316L stainless steel parts produced with SLM technology. Arch. Civ. Mech. Eng. 2014, 14, 608-614. [CrossRef]

16. Aloisi, V.; Carmignato, S. Influence of surface roughness on X-ray computed tomography dimensional measurements of additive manufactured parts. Case Stud. Nondestruct. Test. Eval. 2016, 6, 104-110. [CrossRef]

17. Hastie, J.C.; Kartal, M.E.; Carter, L.N.; Attallah, M.M.; Mulvihill, D.M. Classifying shape of internal pores within AlSi10Mg alloy manufactured by laser powder bed fusion using 3D X-ray micro computed tomography: Influence of processing parameters and heat treatment. Mater. Charact. 2020, 163, 110225. [CrossRef]

18. Moorehead, C.A.; Sietins, J.M.; Swab, J.J. Meso-scale microstructural agglomerate quantification in boron carbide using X-ray microcomputed tomography. Mater. Charact. 2018, 141, 177-185. [CrossRef]

19. Cai, X.; Malcolm, A.A.; Wong, B.S.; Fan, Z. Measurement and characterization of porosity in aluminium selective laser melting parts using X-ray CT. Virtual Phys. Prototyp. 2015, 10, 195-206. [CrossRef]

20. Tremsin, A.S.; Rakovan, J.; Shinohara, T.; Kockelmann, W.; Losko, A.S.; Vogel, S.C. Non-Destructive Study of Bulk Crystallinity and Elemental Composition of Natural Gold Single Crystal Samples by Energy-Resolved Neutron Imaging. Sci. Rep. 2017, 7, 40759. [CrossRef]

21. Brooks, A.J.; Ge, J.; Kirka, M.M.; Dehoff, R.R.; Bilheux, H.Z.; Kardjilov, N.; Manke, I.; Butler, L.G. Porosity detection in electron beam-melted Ti-6Al-4V using high-resolution neutron imaging and grating-based interferometry. Prog. Addit. Manuf. 2017, 2, 125-132. [CrossRef]

22. Trtik, P.; Lehmann, E.H. Isotopically-enriched gadolinium-157 oxysulfide scintillator screens for the high-resolution neutron imaging. Nucl. Instrum. Methods Phys. Res. Sect. A Accel. Spectrometers Detect. Assoc. Equip. 2015, 788, 67-70. [CrossRef] 
23. Trtik, P.; Hovind, J.; Grünzweig, C.; Bollhalder, A.; Thominet, V.; David, C.; Kaestner, A.; Lehmann, E.H. Improving the Spatial Resolution of Neutron Imaging at Paul Scherrer Institut-The Neutron Microscope Project. In Proceedings of the Physics Procedia, Grindelwald, Switzerland, 5-10 October 2014; Volume 69.

24. Trtik, P.; Lehmann, E.H. Progress in High-resolution Neutron Imaging at the Paul Scherrer Institut-The Neutron Microscope Project. J. Phys. Conf. Ser. 2016, 746, 012004. [CrossRef]

25. Trtik, P. Neutron microtomography of voids in gold. MethodsX 2017, 4, 492-497. [CrossRef] [PubMed]

26. Ghasemi-Tabasi, H.; Jhabvala, J.; Boillat, E.; Ivas, T.; Drissi-Daoudi, R.; Logé, R.E. An effective rule for translating optimal selective laser melting processing parameters from one material to another. Addit. Manuf. 2020, 36, 101496. [CrossRef]

27. Kumar, S. Additive Manufacturing Processes, 1st ed.; Springer International Publishing: Berlin/Heidelberg, Germany, 2019; ISBN 978-3-030-45089-2.

28. AlMangour, B.; Grzesiak, D.; Yang, J.-M. Scanning strategies for texture and anisotropy tailoring during selective laser melting of TiC/316L stainless steel nanocomposites. J. Alloys Compd. 2017, 728, 424-435. [CrossRef]

29. Trtik, P.; Meyer, M.; Wehmann, T.; Tengattini, A.; Atkins, D.; Lehmann, E.H.; Strobl, M. PSI 'Neutron Microscope' at ILL-D50 Beamline-First Results. Mater. Res. Proc. 2020, 15, 23-28. [CrossRef]

30. Tengattini, A.; Lenoir, N.; Andò, E.; Giroud, B.; Atkins, D.; Beaucour, J.; Viggiani, G. NeXT-Grenoble, the Neutron and X-ray tomograph in Grenoble. Nucl. Instrum. Methods Phys. Res. Sect. A Accel. Spectrometers Detect. Assoc. Equip. 2020, 968, 163939. [CrossRef]

31. Crha, J.; Vila-Comamala, J.; Lehmann, E.; David, C.; Trtik, P. Light Yield Enhancement of 157-Gadolinium Oxysulfide Scintillator Screens for the High-Resolution Neutron Imaging. MethodsX 2019, 6, 107-114. [CrossRef]

32. Boillat, P.; Carminati, C.; Schmid, F.; Grünzweig, C.; Hovind, J.; Kaestner, A.; Mannes, D.; Morgano, M.; Siegwart, M.; Trtik, P.; et al. Chasing quantitative biases in neutron imaging with scintillator-camera detectors: A practical method with black body grids. Opt. Express 2018, 26, 15769-15784. [CrossRef]

33. Carminati, C.; Boillat, P.; Schmid, F.; Vontobel, P.; Hovind, J.; Morgano, M.; Raventos, M.; Siegwart, M.; Mannes, D.; Gruenzweig, C.; et al. Implementation and assessment of the black body bias correction in quantitative neutron imaging. PLoS ONE 2019, 14, e0210300. [CrossRef] [PubMed]

34. Guizar-Sicairos, M.; Diaz, A.; Holler, M.; Lucas, M.S.; Menzel, A.; Wepf, R.A.; Bunk, O. Phase tomography from x-ray coherent diffractive imaging projections. Opt. Express 2011, 19, 21345-21357. [CrossRef]

35. Kaestner, A.P. MuhRec-A new tomography reconstructor. Nucl. Instruments Methods Phys. Res. Sect. A Accel. Spectrometers, Detect. Assoc. Equip. 2011, 651, 156-160. [CrossRef]

36. Münch, B.; Trtik, P.; Marone, F.; Stampanoni, M. Stripe and ring artifact removal with combined wavelet-Fourier filtering. Opt. Express 2009, 17, 8567-8591. [CrossRef]

37. Carminati, C.; Strobl, M.; Kaestner, A. KipTool, a general purpose processing tool for neutron imaging data. SoftwareX 2019, 10, 100279. [CrossRef]

38. Kaestner, A.; Lehmann, E.; Stampanoni, M. Imaging and image processing in porous media research. Adv. Water Resour. 2008, 31, 1174-1187. [CrossRef]

39. Brown, D.; Kienzle, P. Neutron Activation and Scattering Calculator. Available online: https://www.ncnr.nist.gov / resources / activation/ (accessed on 5 November 2020).

40. Otsu, N. Threshold selection method from gray-level histograms. IEEE Trans. Syst. Man Cybern. 1979, 9, 62-66. [CrossRef]

41. Dong, Z.; Liu, Y.; Wen, W.; Ge, J.; Liang, J. Effect of hatch spacing on melt pool and as-built quality during selective laser melting of stainless steel: Modeling and experimental approaches. Materials 2018, 12, 50. [CrossRef] [PubMed]

42. Du Plessis, A. Effects of process parameters on porosity in laser powder bed fusion revealed by X-ray tomography. Addit. Manuf. 2019, 30, 100871. [CrossRef]

43. DebRoy, T.; Wei, H.L.; Zuback, J.S.; Mukherjee, T.; Elmer, J.W.; Milewski, J.O.; Beese, A.M.; Wilson-Heid, A.; De, A.; Zhang, W. Additive manufacturing of metallic components-Process, structure and properties. Prog. Mater. Sci. 2018, 92, 112-224. [CrossRef]

44. Qi, H.; Azer, M.; Ritter, A. Studies of standard heat treatment effects on microstructure and mechanical properties of laser net shape manufactured INCONEL 718. Metall. Mater. Trans. A Phys. Metall. Mater. Sci. 2009, 40, 2410-2422. [CrossRef]

45. Mancisidor, A.M.; Garciandia, F.; Sebastian, M.S.; Álvarez, P.; Díaz, J.; Unanue, I. Reduction of the residual porosity in parts manufactured by selective laser melting using skywriting and high focus offset strategies. Phys. Procedia 2016, 83, 864-873. [CrossRef]

46. Bian, L.; Shamsaei, N.; Usher, J. Laser-Based Additive Manufacturing of Metal Parts: Modeling, Optimization, and Control of Mechanical Properties, 1st ed.; CRC Press, Inc.: Boca Raton, FL, USA, 2017; ISBN 1498739989. ISBN 9781498739986.

47. Renderos, M.; Torregaray, A.; Gutierrez-Orrantia, M.E.; Lamikiz, A.; Saintier, N.; Girot, F. Microstructure characterization of recycled IN718 powder and resulting laser clad material. Mater. Charact. 2017, 134, 103-113. [CrossRef]

48. Cunningham, R.; Zhao, C.; Parab, N.; Kantzos, C.; Pauza, J.; Fezzaa, K.; Sun, T.; Rollett, A.D. Keyhole threshold and morphology in laser melting revealed by ultrahigh-speed x-ray imaging. Science 2019, 363, 849-852. [CrossRef]

49. Martin, A.A.; Calta, N.P.; Khairallah, S.A.; Wang, J.; Depond, P.J.; Fong, A.Y.; Thampy, V.; Guss, G.M.; Kiss, A.M.; Stone, K.H.; et al. Dynamics of pore formation during laser powder bed fusion additive manufacturing. Nat. Commun. 2019, 10, 1-10. [CrossRef] 
50. Aboulkhair, N.T.; Everitt, N.M.; Ashcroft, I.; Tuck, C. Reducing porosity in AlSi10Mg parts processed by selective laser melting. Addit. Manuf. 2014, 1-4, 77-86. [CrossRef]

51. Griffiths, S.; Ghasemi Tabasi, H.; Ivas, T.; Maeder, X.; De Luca, A.; Zweiacker, K.; Wróbel, R.; Jhabvala, J.; Logé, R.E.; Leinenbach, C. Combining alloy and process modification for micro-crack mitigation in an additively manufactured Ni-base superalloy. Addit. Manuf. 2020, 36, 101443. [CrossRef]

52. Kasperovich, G.; Haubrich, J.; Gussone, J.; Requena, G. Correlation between porosity and processing parameters in TiAl6V4 produced by selective laser melting. Mater. Des. 2016, 112, 160-161. [CrossRef]

53. Lee, J.; Choe, J.; Park, J.; Yu, J.-H.; Kim, S.; Jung, I.D.; Sung, H. Microstructural effects on the tensile and fracture behavior of selective laser melted H13 tool steel under varying conditions. Mater. Charact. 2019, 155, 109817. [CrossRef]

54. Jamshidinia, M.; Kovacevic, R. The influence of heat accumulation on the surface roughness in powder-bed additive manufacturing. Surf. Topogr. Metrol. Prop. 2015, 3, 014003. [CrossRef] 